\title{
Hair-dyeing Effects and Changes in Hair Texture by Arecae Semen Pigment
}

\author{
Ju-Sub Kim \\ Department of Beauty Design, Sangji University, Wonju-si, Gangwon-do, Korea
}

Corresponding author: Ju-Sub Kim, Department of Beauty Design, Sangji University, 84 Sangjidae-gil, Wonju-si, Gangwondo 26339, Korea

Tel.: +82 337300811

Fax: +82 337300811

Email: c-miro@hanmail.net

Received December 16, 2020

Revised January 8, 2021

Accepted January 15, 2021

Published March 30, 2021

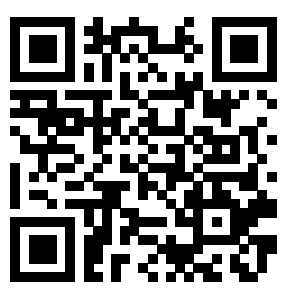

\begin{abstract}
Purpose: This study examines hair-dyeing effects and changes in the characteristics of hair texture by applying Arecae semen pigment to hair. Methods: The Arecae semen pigment was double-boiled and applied to two samples, namely, healthy and bleached hair. The samples were heat-treated and left in natural condition for different hours. The samples were measured before and after application and comparatively analyzed. To quantify the hair-dyeing effects, the $L^{*}, a^{*}$, and $b^{*}$ values as well as fading were measured using a color-difference meter. Additionally, tensile strength, absorbance using methylene blue, and gloss were measured to examine changes in the characteristics of hair texture. Results: The results indicated no changes in the $L^{*}$ value for healthy hair, whereas hair-dyeing effects were observed for $7 \mathrm{~L}(2), 7 \mathrm{~L}(3)$, and $9 \mathrm{~L}(3)$. Analysis of $a^{*}$ and $b^{*}$ values revealed that healthy hair remained the same, whereas significant hair-dyeing effects were noted for $7 \mathrm{~L}(1)$, $7 \mathrm{~L}(2), 7 \mathrm{~L}(3)$, and $9 \mathrm{~L}(3)$. In terms of fading, the most notable fading occurred on Day 1, whereas none was noted on Day 3. Samples $7 \mathrm{~L}(1), 7 \mathrm{~L}(2), 7 \mathrm{~L}(3)$, and $9 \mathrm{~L}(3)$ were used to test for tensile strength, where no changes in hair texture were observed. Furthermore, analysis was conducted on healthy hair and samples $7 \mathrm{~L}(1), 7 \mathrm{~L}(2)$, $7 \mathrm{~L}(3)$, and $9 \mathrm{~L}(3)$ after measuring absorbance using methylene blue. No changes in hair texture were noted. Lastly, the hair samples exhibited no changes after measuring gloss. Conclusions: The study confirmed the hair-dyeing effects of the Arecae Semen pigment. According to hair texture, changes were observed for gloss, whereas tensile strength and absorbance remained the same. In the future, conducting the study on larger samples is necessary to ensure the reliability of results and research on various methods of hair dyeing.
\end{abstract}

Keywords: Arecae semen, Dyeing effect, Hair texture, Hair, Dye

\section{Introduction}

천연염색은 인류의 문명과 같이 시작 되었으며 수렵 또는 채취 활 동 중에 식물의 꽃, 열매, 잎 줄기 등에서 옷감과 신체에 물을 들이기 시작하였고 각 민족은 고유의 색과 염색기법을 다양하게 발전시켜왔 고 과학과 문영이 발달하고 생활이 윤택해짐에 따라 천연 지향의 욕 구가 증대하고 있다(Kim \& Lee, 2003). 이러한 천연염색을 하는 이 유는 화학성분이 첨가되지 않아 피부에 트러블이 적고 색상이 자연 스럽고 예쁘게 표현되기 때문이다. 천연염색은 전통을 계승하고 산 업화를 위한 교육의 중요성이 강조되는 한편 소비자 요구에 대한 천 연염색 종사자들의 관심이 높다(Hong \& Hong, 2008). 이 반면에 모
발 염색 시 염색하기 쉽고 시간적으로 단축되고 다양한 색상으로 지 속성을 위해 합성 염료 원료가 사용되고 있다(Kang \& Ryu, 2019). 헤어 분야에 있어 다양한 색상은 개인의 개성과 이미지 연출을 위 해 그 소비가 증가 추세이나 합성 염색제에 함유된 화학 성분으로 머 릿 결과 두피 손상 등의 부작용이 나타나고 있으며, 현대인들은 인 체에 유해한 염색제 대신 인체에 무해하고 환경오염을 유발하지 않 는 천연염료를 이용한 모발 염색에 관심을 가지고 있다(Oh \& Jung, 2017). 이러한 관심으로 모발과 천연염료와 모발에 관한 연구가 이 루어지고 있다. 연구로는 홍화적새소에 의한 모발 염색의 천연 계면 활성제 첨가에 따른 효과(Bae \& Chang, 2018), 천연 적색파브리카 색소에 의한 모발 염색과 모질의 변화(Kim, 2018), 칡뿌리 추출물 
을 이용한 천연 모발염색(Lee et al., 2010) 등 연구가 꾸준히 이루어 지고 있다. 이러한 천연 염료와 모발과의 연구 중 빈랑자 색소에 대 한 연구는 없는 실정이다. 빈랑자 연구로는 종설: 빈랑의 독성에 관 한 문헌적 고찰(Seo \& Roh)이 있다. 빈랑은 야자과(Palmae)의 잘 익 은 씨로서 열매를 채취하여 물에 삶아 열매 껍질을 벗긴 것이다. 씨 로 둔한 원뿔 모양 또는 납작한 구형이고 그 밑바닥의 중앙에 배꼽점 이 있어 오목하게 들어가며, 길이 $1.5-3.5 \mathrm{~cm}$, 지름 $1.5-3 \mathrm{~cm}$ 이다. 바깥 면은 회적갈색, 회황갈색이며 색이 연한 그물 무늬가 있다(Kim et al., 2014). 갈색색소는 대부분(tannin)게로 거의 모든 나무의 껍 질, 줄기 및 열매에 포함되어 있다(Song \& Kim, 2004). 이러한 갈색 은 탈색 시 모발의 자연 색상과 유사하며 꼭두서니, 소목으로 염색하 여 적색이 들어간 갈색과 같은 다른 염료와 복합하기도 쉬운 색상 계 열이다. 이러한 이유로 빈랑자를 선택하여 연구하고자 하였다. 따라 서 본 연구는 빈랑자 염료로 모발 염색 시에 모발의 염색효과와 모질 의 특성 변화에 영향을 주는지 알아보고자 하였다. 실험을 위해 빈랑 자를 도포 한 후에 방치시간 차이를 두었다. 시료 별로 도포 전과 후 를 비교 분석하였다. 비교 분석은 빈랑자 염료에 의해 모발의 염색효 과를 알아보고자 색차계 측정과 물 빠짐을 측정하였고, 모질의 특성 변화가 있는지 알기 위해 인장강도, 메틸렌블루를 이용한 흡광도 측 정과 광택을 측정 하였다.

\section{Methods}

\section{1. 실험재료}

\section{1) 시료 모발}

실험에 사용된 모발은 최근 2 년 동안 약물복용과 화학적 시술 을 하지 않은 18 세 여성의 모발을 후두부에서 두피 $3 \mathrm{~cm}$ 지점을 기 준으로 $20 \mathrm{~cm}$ 로 채취하여 $2 \mathrm{~g}$ 씩 모(hair) 다발을 만들었다. 플레 인 린스 후 자연건조하여 사용하였다. 빈랑자 염료에 의한 염색력 과 모질의 개선 변화를 연구하기 위하여 화학적시술을 전혀 하지 않은 건강모와 건강 모발에 탈색제 제1제(ammonium persulfate, potassium persulfate, sodium metasilicate, magnesium, sodium carboxymethyl cellulose) (Suanhj, Korea) $3 \mathrm{mg}$ 과 제2제(6\%의 과 산화수소를 주성분으로 water, etidronic acid, phosphoric acid, sodium phosphate dibasic, cetyl alcohol로 구성된 제품) (Suanhj, Korea) $3 \mathrm{~mL}$ 비율로 혼합, 도포하고 $30 \mathrm{~min}$ 방치 후 세척하여 명도 7 레벨 시료 3 다발과 명도 차에 의한 비교를 위해 한번의 탈색을 더 해서 9 레벨의 시료 1 다발을 제작하였다. 실험에 사용된 모발 시료의 level 측정기(level scale, Wella, Germany) 사용하여 측정하였다. 이 시료에 빈랑자 염료를 중탕하여 모발 시료에 도포 전과 후를 비교하 였다.

2) 빈랑자
실험에 사용 한 빈랑자 염료는 원산지는 인도이고 열매에서 추출 한 염료(Toyeon Co., Lt, Korea)를 구입하여 사용하였다.

3) 빈랑자 염료 중탕

분말 염료를 모발에 도포하기 위해서 염료와 정제수 비율을 $1: 3$ 으로 하여 중탕기(P-2000YE; Ims co., Korea) $50^{\circ} \mathrm{C}$ 에서 $1 \mathrm{~h}$ 을 중 탕한 후 $20 \mathrm{~g}$ 씩 모발에 도포하였다

4) 측정기기 및 측정방법

(1) 도포 전, 후의 염색효과 $\left(L^{*}, a^{*}, b^{*}\right)$ 측정

빈랑자 염료로 도포 전과 후의 표면 색상 변화를 알아보고자 색차 계(Color meter, CS-10; CHN spec, China)를 이용하여 CIELAB 표색계의 색상 값인 명도지수 $\mathrm{L}^{*}$ 과 색 좌표 지수인 $\mathrm{a}^{*}$ 와 $\mathrm{b}^{*}$ 값을 측정 하였다.

$\mathrm{L}^{*}$ : CIELAB 표색계의 white-black축에서의 명도지수

$\mathrm{a}^{*}$ : CIELAB 표색계의 red-green 축에서의 채도지수

$\mathrm{b}^{*}$ : CIELAB 표색계의 yellow-blue 축에서의 채도지수

측정값의 신뢰성을 높이기 위해 10 번 측정하여 통계분석을 하였 다.

\section{(2) 물 빠짐 측정}

빈랑자 염료의 물 빠짐 정도를 알기 위해 물 빠짐 측정 방법은 탁 도계(turbidity meter, TU-2016; Lutron electronic, Taiwan) 기기 를 이용하여 측정하였다. $100 \mathrm{~mL}$ 비이커에 정제수를 넣고 시료를 담근 후 $24 \mathrm{~h}$ 후에 탁도를 측정하였다. 측정 기간은 물 빠짐이 없을 때까지 $24 \mathrm{~h}$ 주기로 측정하였다.

물 빠짐 측정을 위해서는 모든 시료를 사용하지는 않고, 가장 명 도가 높은 9 레벨의 시료로 물 빠짐 측정을 하였다.

\section{(3) 인장강도 측정}

염료에 의한 모질의 변화 정도를 알기 위해 모발 시료에 도포 전 과 후의 인장강도를 측정하였다. 측정 기기(Digital force gauge, HF-20; Tripod, China)로 인장강도를 측정하였다. 측정값의 신뢰 성을 위하여 5 회 측정 후 측정하여 통계분석 하였다.

\section{(4) 메틸렌블루를 이용한 흡광도 측정}

염료에 의한 모질의 변화 정도를 알기 위해 모발 시료에 도포 전 과 후의 흡광도를 측정하였다. 측정기기로는 모발의 외경은 마이 크로미터(Quickmike, Mitutoyo)를 이용하여 0.070-0.075 mm 의 굵기 오차범위를 정하고 $5 \mathrm{~cm}$ 의 길이 잘랐다. 자른 모발을 tube 에 넣은 후 MB solution에 담가 vortex mixer (Vortex genie 2, Scientific Industries, USA)를 이용하여 $10 \mathrm{~s}$ 동안 vortexing하였 다. $50^{\circ} \mathrm{C}$ heat block (wise therm HB-48P; Daihan Scientific, Korea)에서 $10 \mathrm{~min}$ 간 유지하여 $\mathrm{MB}$ solution을 흡착시키고, tube 
에 있는 3 가닥의 시료를 꺼내어 표면에 묻어있는 MB solution은 실 험용 티슈를 이용하여 제거하고, 시료 3 가닥을 각각 새 tube에 옮 겨 담았다. 이 tube에 $\mathrm{NR}$ desorb solution을 $5 \mathrm{~mL}$ 를 넣고 상온에 서 $5 \mathrm{~min}$ 방치 후 $10 \mathrm{~s}$ vortexing 후 추출하였다. 추출한 용액을 큐 벳(cuvettes)에 $3000 \mu \mathrm{L}$ 분주하여 $\mathrm{MB}$ 의 흡수 강도가 가장 높은 파 장인 $660 \mathrm{~nm}$ 로 흡광도를 측정하였다. 모다발 별로 3 가닥씩 같은 방법으로 측정하여 통계 분석하였다. 측정 시 기준 값을 잡기 위해 desorb solution을 $3000 \mu \mathrm{L}$ 분주하여 blank를 만들어준다. $\mathrm{MB}$ 시 약은 DW $20 \mathrm{~mL}+\mathrm{MB} 400 \mu \mathrm{L}$ 으로 희석하여 $2 \%$ 로 만들어 사용하 였다. NR solution은 $49 \%$ ethanol $(49 \mathrm{~mL})+1 \%$ glacial aceticacid $(1 \mathrm{~mL})+50 \% \mathrm{DW}(50 \mathrm{~mL})$ 의 비율로 완성하였다.

\section{(5) 모발 표면 광택 측정}

염료에 의한 모질의 변화 정도를 알기 위해 모발 시료에 도포 전 과 후의 광택 변화를 측정하였다. 측정기기는 광택계(Gloss meter NHG268; Shenzhen Threenh Technology, China)를 이용하여 측 정하였다. 측정값의 신뢰성을 높이기 위해 10 번 측정하여 통계 분 석하였다.

\section{5) 도포 실험방법}

건강모와 탈색으로 시술 한 모발 시료 7레벨, 9 레벨 시료에 중탕 한 염료를 각각의 시료에 $20 \mathrm{~g}$ 도포하였다. 도포 후 방치시간을 다 르게 하였다. 방치시간 후에 세척하여 자연건조 시켜 측정하였다. 도포는 도포량, 자연방치시간, 열처리 시간, 시술자의 숙련도에 등 에 따라서 측정과 결과에 차이가 있을 수 있기 때문에 최대한 차이 를 줄이기 위해 시술자는 각 단계별로 동일인이 시술하였다. 각 레 벨과 방치시간에 따른 시료 표기는 Table 1과 같다. $7 \mathrm{~L}(1)$ 시료는 7 레벨의 모발에 빈랑자를 $20 \mathrm{~g}$ 도포 후 자연방치 $30 \mathrm{~min}, 7 \mathrm{~L}(2)$ 시
료는 7레벨의 모발에 빈랑자를 $20 \mathrm{~g}$ 도포 후 열처리 $10 \mathrm{~min}$ 과 자 연방치 $20 \mathrm{~min}, 7 \mathrm{~L}(3)$ 시료는 7레벨의 모발에 빈랑자를 $20 \mathrm{~g}$ 도포 후 열처리 $20 \mathrm{~min}$ 과 자연방치 $10 \mathrm{~min}, 9 \mathrm{~L}(3)$ 시료는 9 레벨의 모 발에 빈랑자를 $20 \mathrm{~g}$ 도포 후 열처리 $20 \mathrm{~min}$ 과 자연방치 $10 \mathrm{~min}$ 을 하였다.

\section{6) 결과 분석}

각 항목의 실험은 실험에 따라 표면색 변화와 광택측정은 10 회, 인장강도는 5 회 측정, 흡광도는 3 회 측정한 값을 도포 전과 후를 비 교하였다. 신뢰성과 객관성을 높이기 위한 통계분석을 위해 평균 (mean), 표준편차(standard division, $\mathrm{SD}$ )를 구하고 사후 검증으로 통계 프로그램인 jamovi 1.2.27 solid를 이용하여 $t$-tests (paired sample $t$-test)로 양측검정(two tailed test)실시하였고, 유의 수준 은 $p<0.05$ 수준에서 검증하였다. 귀무가설은 "도포 전과 후의 차이 가 없다"이고 연구가설은 "도포 전과 후의 차이가 있다"로 하였다.

\section{Results and Discussion}

\section{1. 빈랑자 염료에 따른 도포 전, 후의 염색 효과 측정}

천연 염료의 연구 개발은 꾸준히 이루어지고 있다. 천연 빈랑자 염료로 시료에 도포 전·후 염색효과를 측정 한 결과 다음과 같다.

1) 시료 별 $L^{*}$ 측정

빈랑자 염료로 시료에 도포 전과 후 통계 분석 결과 $\mathrm{L}^{*}$ 값은 Table 2 와 같다. 도포전 같은 7 레벨의 $\mathrm{L}^{*}$ 값이 차이가 나는 것은 모다발 별로 모질의 차이에 의한 것이다. 건강모시료에 빈랑자 염료로 도포 전 평균 값은 15.5 이고 도포 후의 값은 15.0 으로 0.5 차이를 나타낸 다. 이런 차이가 표본을 추출 할 때 발생하는 표본 오차에 의한 차이

Table 1. Expression method for samples

\begin{tabular}{ll}
\hline Sample & \multicolumn{1}{c}{ Contents } \\
\hline Virgin hair & Undamaged hair (natural drying $30 \mathrm{~min})$ \\
$7 \mathrm{~L}(1)$ & Treatment of level-7 sample with Arecae semen $20 \mathrm{~g}$ (natural drying $30 \mathrm{~min}$ ) \\
$7 \mathrm{~L}(2)$ & Treatment of level-7 sample with Arecae semen $20 \mathrm{~g}$ (heat treatment $10 \mathrm{~min}+$ natural drying $20 \mathrm{~min}$ ) \\
$7 \mathrm{~L}(3)$ & Treatment of level-7 sample with Arecae semen $20 \mathrm{~g}$ (heat treatment $20 \mathrm{~min}+$ natural drying10 min ) \\
$9 \mathrm{~L}(3)$ & Treatment of level-7 sample with Arecae semen $20 \mathrm{~g}$ (heat treatment 20 min +natural drying 10 min ) \\
\hline
\end{tabular}

Table 2. Statistical analysis result value of brightness $L^{*}$

\begin{tabular}{|c|c|c|c|c|c|}
\hline Sample & & Pre & Post & Statistic & $p$ \\
\hline Virgin hair & $\mathrm{L}^{*}$ & $15.5 \pm 0.34^{1)}$ & $15.0 \pm 2.08$ & 0.603 & 0.562 \\
\hline $7 \mathrm{~L}(1)$ & $\mathrm{L}^{*}$ & $43.2 \pm 0.23$ & $42.9 \pm 0.79$ & 0.943 & 0.370 \\
\hline $7 \mathrm{~L}(2)$ & $\mathrm{L}^{*}$ & $42.6 \pm 1.71$ & $41.7 \pm 1.41$ & -3.120 & $0.012^{*}$ \\
\hline $7 \mathrm{~L}(3)$ & $\mathrm{L}^{*}$ & $46.7 \pm 0.73$ & $39.0 \pm 0.44$ & 30.200 & $0.001^{*}$ \\
\hline $9 \mathrm{~L}(3)$ & $\mathrm{L}^{*}$ & $58.8 \pm 0.73$ & $47.3 \pm 1.87$ & 27.600 & $0.001^{*}$ \\
\hline
\end{tabular}

${ }^{1)}$ Mean $\pm S D ;{ }^{*} p<0.05$. 
인지 아니면 모평균 차이에 의한 것이지 판단하기 위해 모든 시료에 대응표본 $t$-검정을 통해 검정하였다. 유의확률( $p$-value) 0.562 로 유의기준 $p<0.05$ 보다 큰 값으로 비유의미적 결과를 알 수 있었다. 이는 연구가설이 기각되어 건강모에서는 염료에 의한 $\mathrm{L}^{*}$ 값 변화가 없는 것을 알 수 있었다. 이는 염료가 건강한 모발의 모표피에 흡착 이 되지 못한 결과로 사료된다. $7 \mathrm{~L}(1)$ 시료는 도포 전 평균값이 43.2 이고 도포 후 값은 42.9 로 0.3 차이를 나타낸다. 검정결과 유의확률 이 0.370 으로 유의기준 $p<0.05$ 보다 큰 값으로 비유의적 결과를 알 수 있었다. 건강모와 마찬가지로 $\mathrm{L}^{*}$ 값 변화가 없는 것을 알 수 있 었다. 이는 방치 타임을 자연방치로만 $30 \mathrm{~min}$ 한 결과로 사료된다. $7 \mathrm{~L}(2)$ 시료는 도포 전 평균값이 42.6 이고 도포 후의 값은 41.7 로 0.9 차이를 나타낸다. 검정결과 유의확률이 0.012 로 유의 기준 $p<0.05$ 보다 작은 값으로 유의미한 결과를 알 수 있었다. 연구가설을 채택 할 수 있어 $\mathrm{L}^{*}$ 값 변화가 있는 것을 알 수 있었다. 이는 방치타임 시 열처리를 $10 \mathrm{~min}$ 과 자연방치 $20 \mathrm{~min}$ 을 한 결과로 사료된다. $7 \mathrm{~L}(3)$ 시료는 도포 전 평균값이 46.7 이고 도포 후의 값은 39.0 으로 7.7차 이를 나타낸다. 검정결과 유의확률이 0.001 로 유의 기준 $p<0.05$ 보 다 작은 값으로 유의미한 결과를 알 수 있었다. 연구가설을 채택 할 수 있어 $\mathrm{L}^{*}$ 값 변화가 있는 것을 알 수 있었다. 이는 방치타임 시 열 처리를 $20 \mathrm{~min}$ 과 자연방치 $10 \mathrm{~min}$ 을 한 결과로 사료된다. $9 \mathrm{~L}(3)$ 시 료는 도포 전 평균값이 58.8 이고 도포 후의 값은 47.3 으로 11.5 차이 를 나타낸다. 검정결과 유의확률이 0.001 로 유의 기준 $p<0.05$ 보다 작은 값으로 유의미한 결과를 알 수 있었다. 연구가설을 채택 할 수 있어 $\mathrm{L}^{*}$ 값 변화가 있는 것을 알 수 있었다. 이는 $7 \mathrm{~L}(3)$ 시료와 마찬 가지로 방치타임 시 열처리를 $20 \mathrm{~min}$ 과 자연방치 10 분을 한 결과로 사료된다. 염착에 의한 $\mathrm{L}^{*}$ 값은 시료의 명도가 높을수록 또는 방치타 임 시 열처리를 할수록 높은 값의 차이를 보인다는 것을 알 수 있었 고 도포 후의 $\mathrm{L}^{*}$ 값이 감소함을 알 수 있었다. 헤어컬러 시 온도가 높
을수록 염착 반응이 빨라 염착이 되기 쉽다(Kim, 2017)는 내용과 같 은 결과이다.

\section{2) 시료 별 $a^{*}$ 측정}

빈랑자 염료로 시료에 도포 전과 후 통계분석 결과 $\mathrm{a}^{*}$ 값은 Table 3 과 같다. 도포 전 같은 7 레벨의 $\mathrm{a}^{*}$ 값이 차이가 나는 것은 모다발 별로 모질의 차이에 의한 것이다. 건강모시료에 도포 전과 후 평균 값은 0.99 로 차이를 나타낸다. 이런 차이가 표본을 추출 할 때 발생 하는 표본 오차에 의한 차이인지 아니면 모평균 차이에 의한 것이 지 판단하기 위해 대응표본 $t$-검정을 통해 검정하였다. 유의확률 ( $p$-value) 0.095 로 유의기준 $p<0.05$ 보다 큰 값으로 비유의미적 결 과를 알 수 있었다. 이는 연구가설이 기각되어 건강모에서는 염료에 의한 $\mathrm{a}^{*}$ 값 변화가 없는 것을 알 수 있었다. $7 \mathrm{~L}(1)$ 시료에 도포 전과 후의 평균값은 3.3 차이를 나타낸다. 검정결과 유의확률이 0.001 로 유의기준 $p<0.05$ 보다 작은 값으로 유의미한 결과를 알 수 있었다. $\mathrm{L}^{*}$ 값의 결과와 다르게 변화를 주는 것을 알 수 있었다. 이는 빈랑자 염료가 회적갈색을 띄기 때문으로 사료된다. $7 \mathrm{~L}(2)$ 시료에 도포 전과 후의 평균값은 2.6 차이를 나타낸다. 검정결과 유의확률이 0.001 로 유의기준 $p<0.05$ 보다 작은 값으로 유의미한 결과를 알 수 있었다. $\mathrm{a}^{*}$ 값 변화를 주는 것을 알 수 있었다. $7 \mathrm{~L}(3)$ 시료에 도포 전과 후의 평균값은 8.6 차이를 나타낸다. 검정결과 유의확률이 0.001 로 유의 기준 $p<0.05$ 보다 작은 값으로 유의미한 결과를 알 수 있었다. $\mathrm{a}^{*}$ 값 변화를 주는 것을 알 수 있었다. $9 \mathrm{~L}(3)$ 시료에 도포 전과 후의 평균값 은 12.01 차이를 나타낸다. 검정결과 유의확률이 0.001 로 유의기준 $p<0.05$ 보다 작은 값으로 유의미한 결과를 알 수 있었다. $\mathrm{a}^{*}$ 값 증가 로 표면 색상 변화를 주는 것을 알 수 있었다. 이는 침척시간이 길수 록 염색성이 높아지는 경향을 보였다(Cha \& Kim, 2008)는 결과와 유사함을 알 수 있었다.

Table 3. Statistical analysis result value of $a^{\text {* }}$

\begin{tabular}{llcccc}
\hline Sample & & Pre & Post & Statistic & $p$ \\
Virgin hair & $\mathrm{a}^{*}$ & $-8.69 \pm 0.35^{1)}$ & $-7.70 \pm 1.63$ & -1.87 & 0.095 \\
$7 \mathrm{~L}(1)$ & $\mathrm{a}^{*}$ & $11.8 \pm 0.23$ & $15.1 \pm 0.50$ & -16.60 & $0.001^{*}$ \\
$7 \mathrm{~L}(2)$ & $\mathrm{a}^{*}$ & $13.8 \pm 1.03$ & $15.6 \pm 0.84$ & -5.04 & $0.001^{*}$ \\
$7 \mathrm{~L}(3)$ & $\mathrm{a}^{*}$ & $11.8 \pm 0.94$ & $20.4 \pm 0.75$ & -19.20 & $0.001^{*}$ \\
$9 \mathrm{~L}(3)$ & $\mathrm{a}^{*}$ & $4.69 \pm 0.35$ & $16.7 \pm 0.64$ & -64.60 & $0.001^{*}$ \\
\hline
\end{tabular}

${ }^{1)}$ Mean $\pm S D ;{ }^{*} p<0.05$.

Table 4. Statistical analysis result value of $b^{*}$

\begin{tabular}{llllll}
\hline Sample & & Pre & Post & Statistic & $p$ \\
Virgin hair & $\mathrm{b}^{*}$ & $0.24 \pm 0.38^{1)}$ & $0.65 \pm 0.68$ & -1.66 & 0.132 \\
$7 \mathrm{~L}(1)$ & $\mathrm{b}^{*}$ & $37.8 \pm 0.36$ & $41.0 \pm 1.09$ & -8.42 & $0.001^{*}$ \\
$7 \mathrm{~L}(2)$ & $\mathrm{b}^{*}$ & $38.1 \pm 1.54$ & $41.4 \pm 1.82$ & -4.36 & $0.002^{*}$ \\
$7 \mathrm{~L}(3)$ & $\mathrm{b}^{*}$ & $35.9 \pm 1.18$ & $48.9 \pm 1.37$ & -20.30 & $0.001^{*}$ \\
$9 \mathrm{~L}(3)$ & $\mathrm{b}^{*}$ & $29.4 \pm 0.418$ & $41.5 \pm 1.22$ & -35.70 & $0.001^{*}$ \\
\hline
\end{tabular}

\footnotetext{
${ }^{1)}$ Mean \pm SD; ${ }^{*} p<0.05$.
} 


\section{3) 시료별 $b^{*}$ 측정}

빈랑자 염료로 시료에 도포 전과 후 통계분석 결과 $b^{*}$ 값은 Table 4 와 같다. 도포 전 같은 7 레벨의 $b^{*}$ 값이 차이가 나는 것은 모다발 별 로 모질의 차이에 의한 것이다. 건강모시료에 도포 전과 후 평균 값 은 0.41 로 차이를 나타낸다. 이런 차이가 표본을 추출 할 때 발생 하는 표본 오차에 의한 차이인지 아니면 모평균 차이에 의한 것이 지 판단하기 위해 대응표본 $t$-검정을 통해 검정하였다. 유의확률 ( $p$-value) 0.132 로 유의기준 $p<0.05$ 보다 큰 값으로 비유의미적 결 과를 알 수 있었다. 이는 연구가설이 기각되어 건강모에서는 염료에 의한 $b^{*}$ 값 변화가 없는 것을 알 수 있었다. $7 \mathrm{~L}(1)$ 시료에 도포 전과 후 의 평균값은 3.2 차이를 나타낸다. 검정결과 유의확률이 0.001 로 유 의기준 $p<0.05$ 보다 작은 값으로 유의미한 결과를 알 수 있었다. 이 는 빈랑자 염료가 회적갈색과 같이 회황갈색을 띄기 때문으로 사료된 다. $7 \mathrm{~L}(2)$ 시료에 도포 전과 후의 평균값은 3.3 차이를 나타낸다. 검정 결과 유의확률이 0.002 로 유의기준 $p<0.05$ 보다 작은 값으로 유의미 한 결과를 알 수 있었다. $b^{*}$ 값 변화를 주는 것을 알 수 있었다. $7 \mathrm{~L}(3)$ 시료에 도포 전과 후의 평균값은 13.0 차이를 나타낸다. 검정결과 유 의확률이 0.001 로 유의기준 $p<0.05$ 보다 작은 값으로 유의미한 결과 를 알 수 있었다. b* 값 변화를 주는 것을 알 수 있었다. $9 \mathrm{~L}(3)$ 시료에 도포 전과 후의 평균값은 12.1 차이를 나타낸다. 검정결과 유의확률 이 0.001 로 유의기준 $p<0.05$ 보다 작은 값으로 유의미한 결과를 알 수 있었다. $b^{*}$ 값 증가로 표면 색상 변화를 주는 것을 알 수 있었다. 이는 온도에 따른 $\mathrm{b}^{*}$ 값의 염색 시간이 증가할수록 증가한다(Baek et al., 2017)는 결과와 유사와 결과임을 알 수 있었다.

\section{2. 물 빠짐 측정}

빈랑자 염료로 도포한 시료의 물 빠짐 측정 결과는 Table 5 와 같 다. 물 빠짐 측정을 위해서 가장 명도가 높은 9 레벨의 시료로 물 빠 짐 측정을 하였다. 이는 9 레벨의 모발 손상이 7레벨보다 손상이 심할 것으로 판단하였기 때문이다. 측정결과 1 일차에는 가장 많이 20.67 $\mathrm{NTU}$ 가 빠졌고, 2 일차에는 $12.90,3$ 일차에는 3.76 이고, 4 일차부터
더 이상의 물 빠짐이 없었다. 빈랑자가 거의 무색에 가깝지만 조금의 색을 가지고 있는 것으로 사료되며, 1-3 일차까지 물 빠짐이 있는 이 유는 그 만큼 오일이 모발에 깊이 침투, 흡착이 된 것으로 사료된다. 1-3 일 차까지 미비하지만 물 빠짐이 일어난 이유는 모발의 손상으 로 인한 색의 유실(Kim \& Yoo, 2019)의 결과 인 것으로 사료된다.

\section{3. 시료 별의 인장강도 측정}

빈랑자 염료로 시료에 도포 전, 후 인장강도 측정 결과는 Table 6 과 같다. 도포 전 같은 7 레벨의 인장강도 값이 차이가 나는 것은 모 다발 별로 모질의 차이에 의한 것이다. 건강모시료에 도포 전과 후 평균 값은 0.03 차이를 나타낸다. 이런 차이가 표본을 추출 할 때 발 생하는 표본 오차에 의한 차이인지 아니면 모평균 차이에 의한 것이 지 판단하기 위해 모든 시료에 대응표본 $t$-검정을 통해 검정하였다. 유의확률 ( $p$-value) 0.762 로 유의기준 $p<0.05$ 보다 큰 값으로 비유의 적 결과를 알 수 있었다. 이는 연구가설이 기각되어 건강모에서는 염 료에 의한 인장강도 변화가 없는 것을 알 수 있었다. $7 \mathrm{~L}(1)$ 시료에 도 포 전과 후의 평균값은 0.08 차이를 나타낸다. 검정결과 유의확률이 0.463 으로 유의기준 $p<0.05$ 보다 큰 값으로 비유의적 결과를 알 수 있어 염료에 의한 인장강도 변화는 없는 것을 알 수 있었다. $7 \mathrm{~L}(2)$ 시 료에 도포 전과 후의 평균값은 차이가 없음을 나타낸다. 검정결과 유 의확률이 0.973 으로 유의기준 $p<0.05$ 보다 큰 값으로 비유의적 결 과를 알 수 있어 인장강도 변화가 없음을 알 수 있었다. $7 \mathrm{~L}(3)$ 시료에 도포 전과 후의 평균값은 0.99 차이를 나타낸다. 검정결과 유의확률 이 0.271 로 유의기준 $p<0.05$ 보다 큰 값으로 비유의적 결과를 알 수 있어 인장강도 변화가 없음을 알 수 있었다. $9 \mathrm{~L}(3)$ 시료에 도포 전과 후의 평균값은 0.06 차이를 나타낸다. 검정결과 유의확률이 0.318 로 유의기준 $p<0.05$ 보다 큰 값으로 비유의적 결과를 알 수 있어 인장 강도 변화가 없음을 알 수 있었다. 7레벨과 9레벨 시료에서의 인장 강도 평균값 변화는 도포 후에 증가하였다. 이는 7,9 레벨에 백련초 를 도포한 시료들의 인장강도가 증가하였다(Kim \& You, 2019)는 결 과와 같음을 알 수 있었다. 그러나 통계분석 결과는 비유의적 결과로 나와 인장강도 변화가 없음을 알 수 있었다.

Table 5. Pigment loss

(Unit: NTU)

\begin{tabular}{llccc}
\hline Sample $9 \mathrm{~L}(3)$ & 1 day & 2 day & 3 day & 4 day \\
Pigment loss value & 20.67 & 12.90 & 3.76 & 0 \\
\hline
\end{tabular}

Table 6. Statistical analysis result value of tensile strength

\begin{tabular}{lcccc}
\hline Sample & Pre & Post & Statistic & $p$ \\
Virgin hair & $1.20 \pm 0.24^{1)}$ & $1.17 \pm 0.12$ & 0.324 & 0.762 \\
$7 \mathrm{~L}(1)$ & $1.02 \pm 0.08$ & $1.10 \pm 0.15$ & -0.81 & 0.463 \\
$7 \mathrm{~L}(2)$ & $1.01 \pm 0.15$ & $1.01 \pm 0.26$ & 0.03 & 0.973 \\
$7 \mathrm{~L}(3)$ & $0.98 \pm 0.09$ & $1.07 \pm 0.15$ & -1.28 & 0.271 \\
$9 \mathrm{~L}(3)$ & $0.56 \pm 0.08$ & $0.62 \pm 0.08$ & -1.14 & 0.318 \\
\hline
\end{tabular}

\footnotetext{
${ }^{1)}$ Mean \pm SD.
} 


\section{4. 시료 별의 메틸렌블루를 이용한 흡광도 측정}

빈랑자 염료로 시료에 도포 전, 후 흡광도 측정 결과는 Table 7 과 같다. 도포 전 같은 7 레벨의 흡광도 값이 차이가 나는 것은 모다 발 별로 모질의 차이에 의한 것이다. 건강모시료에 도포 전과 후 평 균 값은 0.01 차이를 나타낸다. 이런 차이가 표본을 추출 할 때 발생 하는 표본 오차에 의한 차이인지 아니면 모평균 차이에 의한 것이지 판단하기 위해 모든 시료에 대응표본 $t$-검정을 통해 검정하였다. 유 의확률( $p$-value) 0.164 로 유의기준 $p<0.05$ 보다 큰 값으로 비유의 적 결과를 알 수 있었다. 이는 연구가설이 기각되어 건강모에서는 염 료에 의한 흡광도 변화가 없는 것을 알 수 있었다. $7 \mathrm{~L}(1)$ 시료에 도 포 전과 후의 평균값은 0.02 차이를 나타낸다. 검정결과 유의확률이 0.270 으로 유의기준 $p<0.05$ 보다 큰 값으로 비유의적 결과를 알 수 있어 염료에 의한 흡광도 변화는 없는 것을 알 수 있었다. $7 \mathrm{~L}(2)$ 시료 에 도포 전과 후의 평균값은 0.07 차이를 나타낸다. 검정결과 유의확 률이 0.252 로 유의기준 $p<0.05$ 보다 큰 값으로 비유의적 결과를 알 수 있어 흡광도 변화가 없음을 알 수 있었다. $7 \mathrm{~L}(3)$ 시료에 도포 전과 후의 평균값은 0.01 차이를 나타낸다. 검정결과 유의확률이 0.184 로 유의기준 $p<0.05$ 보다 큰 값으로 비유의적 결과를 알 수 있어 흡 광도 변화가 없음을 알 수 있었다. $9 \mathrm{~L}(3)$ 시료에 도포 전과 후의 평균 값은 0.12 차이를 나타낸다. 검정결과 유의확률이 0.241 로 유의기준 $p<0.05$ 보다 큰 값으로 비유의적 결과를 알 수 있어 흡광도 변화가 없음을 알 수 있었다. 7 레벨과 9 레벨 시료에서의 흡광도 평균값 변 화는 도포 후에 감소하였다. 이는 7, 9레벨에 자색고구마를 도포한 시료들의 흡광도가 감소하였다(Kim, 2020)는 결과와 같음을 알 수 있었다. 그러나 통계분석 결과는 비유의적 결과로 나와 흡광도 변화 가 없음을 알 수 있었다.

\section{5. 시료 별의 광택 측정}

빈랑자 염료로 시료에 도포 전, 후 광택 측정 결과는 Table 8과 같 다. 도포 전 같은 7 레벨의 광택 값이 차이가 나는 것은 모다발 별로 모질의 차이에 의한 것이다.

건강모시료에 도포 전과 후 평균 값은 0.38 차이를 나타낸다. 이 런 차이가 표본을 추출 할 때 발생하는 표본 오차에 의한 차이인지 아 니면 모평균 차이에 의한 것이지 판단하기 위해 모든 시료에 대응표 본 $t$-검정을 통해 검정하였다. 유의확률( $p$-value) 0.418 로 유의기 준 $p<0.05$ 보다 큰 값으로 비유의적 결과를 알 수 있었다. 이는 연구 가설이 기각되어 건강모에서는 염료에 의한 광택 변화가 없는 것을 알 수 있었다. $7 \mathrm{~L}(1)$ 시료에 도포 전과 후의 평균값은 0.16 차이를 나 타낸다. 검정결과 유의확률이 0.006 으로 유의기준 $p<0.05$ 보다 작은 값으로 유의미한 결과를 알 수 있어 염료에 의한 광택 변화가 있는 것 을 알 수 있었다. $7 \mathrm{~L}(2)$ 시료에 도포 전과 후의 평균값은 0.37 차이를 나타낸다. 검정결과 유의확률이 0.001 로 유의기준 $p<0.05$ 보다 작은 값으로 유의미한 결과를 알 수 있어 염료에 의한 광택 변화가 있는 것 을 알 수 있었다. $7 \mathrm{~L}(3)$ 시료에 도포 전과 후의 평균값은 0.22 차이를 나타낸다. 검정결과 유의확률이 0.040 로 유의기준 $p<0.05$ 보다 작은 값으로 유의미한 결과를 알 수 있어 염료에 의한 광택 변화가 있는 것 을 알 수 있었다. $9 \mathrm{~L}(3)$ 시료에 도포 전과 후의 평균값은 0.36 차이를 나타낸다. 검정결과 유의확률이 0.001 로 유의기준 $p<0.05$ 보다 작은 값으로 유의미한 결과를 알 수 있어 염료에 의한 광택 변화가 있는 것 을 알 수 있었다. 7레벨 시료에서의 광택 평균값 변화는 증가하였고, 9 레벨 시료에서의 광택 평균값 변화는 도포 후에 감소하였다. 이는 빈랑자 염료가 탈색을 많이 한 9레벨 시료에 염착이 되어 오히려 광 택이 감소하는 변화를 주고, 갈색 계열에 속하는 7레벨 시료에는 황 색계의 빈랑자 염료가 광택이 증가하는 변화를 준 것으로 사료된다.

Table 7. Statistical analysis result value of optical density

\begin{tabular}{lcccc}
\hline Sample & Pre & Post & Statistic & $p$ \\
Virgin hair & $0.05 \pm 0.00^{1)}$ & $0.04 \pm 0.00$ & 3.80 & 0.164 \\
$7 \mathrm{~L}(1)$ & $0.15 \pm 0.03$ & $0.13 \pm 0.01$ & 2.16 & 0.270 \\
$7 \mathrm{~L}(2)$ & $0.21 \pm 0.06$ & $0.14 \pm 0.02$ & 2.39 & 0.252 \\
$7 \mathrm{~L}(3)$ & $0.17 \pm 0.01$ & $0.16 \pm 0.01$ & 3.36 & 0.184 \\
$9 \mathrm{~L}(3)$ & $0.27 \pm 0.01$ & $0.15 \pm 0.05$ & 2.51 & 0.241 \\
\hline
\end{tabular}

${ }^{1)}$ Mean \pm SD.

Table 8. Statistical analysis result value of gloss meter

(Unit: GU)

\begin{tabular}{lcccc}
\hline Sample & Pre & Post & Statistic & $p$ \\
Virgin hair & $0.90 \pm 1.44^{1)}$ & $0.52 \pm 0.09$ & 0.84 & 0.418 \\
$7 \mathrm{~L}(1)$ & $0.96 \pm 0.08$ & $1.12 \pm 0.07$ & -3.54 & $0.006^{*}$ \\
$7 \mathrm{~L}(2)$ & $1.18 \pm 0.15$ & $1.55 \pm 0.05$ & -6.62 & $0.001^{*}$ \\
$7 \mathrm{~L}(3)$ & $0.87 \pm 0.30$ & $1.09 \pm 0.08$ & -2.40 & $0.040^{*}$ \\
$9 \mathrm{~L}(3)$ & $1.51 \pm 0.07$ & $1.15 \pm 0.08$ & 16.30 & $0.001^{*}$ \\
\hline
\end{tabular}

${ }^{1)}$ Mean \pm SD; ${ }^{*} p<0.05$. 


\section{Conclusion}

본 연구는 빈랑자 염료로 건강모와 탈색한 7레벨, 9레벨 시료에 도포하여 도포 전과 후의 염색 효과와 염료에 의한 모질의 특성 변화 가 있는지를 연구하였다. 빈랑자 분말 염료를 정제수와 혼합 후 중 탕하여 시료에 도포하였다. 방치 한 후 플레인 린스 하여 모발을 자 연 건조하였다. 건조한 시료의 도포 전, 후의 염색효과를 측정하고자 $\mathrm{L}^{*}, \mathrm{a}^{*}, \mathrm{~b}^{*}$ 값, 물 빠짐 값을 비교 분석하였고, 모질의 특성 변화를 알 기 위해 인장강도, 메틸렌블루를 이용한 흡광도, 광택 측정을 하였 다. 그 결과 다음과 같은 결론을 얻었다.

첫째, 모발 염색효과를 알기 위한 $\mathrm{L}^{*}, \mathrm{a}^{*}, \mathrm{~b}^{*}$ 값 측정 결과로 $\mathrm{L}^{*}$ 값 은 건강모의 경우 L"값은 통계분석 결과 변화가 없음을 알 수 있었 고, $7 \mathrm{~L}(2)$ 과 $7 \mathrm{~L}(3), 9 \mathrm{~L}(3)$ 은 변화가 있는 것으로 염색 효과가 있음을 알 수 있었다. $a^{*}$ 값과 $b^{*}$ 값은 도포 전과 후의 통계분석 결과 건강모 는 변화가 없음을 알 수 있었고, $7 \mathrm{~L}(1)$ 과 $7 \mathrm{~L}(2), 7 \mathrm{~L}(3), 9 \mathrm{~L}(3)$ 은 유의 미한 결과로 염색 효과가 있음을 알 수 있었다.

둘째, 빈랑자 염료 의 물 빠짐을 알기 위한 측정 결과로는 1 일차에 는 가장 많이 빠졌고, 4 일차부터는 더 이상의 물 빠짐이 없었다.

셋째, 모질의 특성 변화를 알기 위한 인장강도 측정 결과는 $7 \mathrm{~L}(1)$ 과 $7 \mathrm{~L}(2), 7 \mathrm{~L}(3), 9 \mathrm{~L}(3)$ 모두 평균값은 증가함을 알 수 있었으나, 통 계분석으로는 변화가 없음을 알 수 있었다.

넷째, 모질의 특성 변화를 알기 위한 흡광도 측정 결과는 건강모 와 $7 \mathrm{~L}(1)$ 과 $7 \mathrm{~L}(2), 7 \mathrm{~L}(3), 9 \mathrm{~L}(3)$ 모두 평균값은 감소함을 알 수 있었 으나, 통계분석으로는 변화가 없음을 알 수 있었다.

다섯째, 모질의 특성 변화를 알기 위한 광택 측정 결과는 $7 \mathrm{~L}(1)$ 과 $7 \mathrm{~L}(2), 7 \mathrm{~L}(3)$ 에서는 평균값이 증가하고, $9 \mathrm{~L}(3)$ 에서는 감소하였다. 통 계분석으로 유의미한 결과로 광택에 변화를 주는 것을 알 수 있었다.

이와 같은 결과로 빈랑자 염료로 모발에 도포 시 염색 효과가 있음 을 알 수 있었고, 모질의 특성 변화는 통계분석 결과 흡광도와 인장 강도 변화는 없는 것을 알 수 있었고, 광택에는 변화를 주는 것을 알 수 있었다. 이로서 모발 염모제 성분으로 사용 가능 함을 알 수 있었 다.

천연 염료와 모발에 대한 연구가 이루어지고 있지만 다양한 연구 방법의 염색효과 측정과 모질 특성 변화에 관한 연구는 미비한 실정 이다. 차후 연구 시 염색효과를 측정을 위해 다양한 경우의 처리방법 에 의한 연구가 필요하고 신뢰성과 객관적 결과를 위한 모질의 특성 변화 측정을 위해서는 측정 회수를 늘려서 연구 할 필요가 있다.

\section{Author's contribution}

JSK designed all experimental investigations, and collected Arecae semen data, and wrote the manuscript.

\section{Author details}

Ju-Sub Kim (Professor), Department of Beauty Design,
Sangji University, 84 Sangjidae-gil, Wonju-si, Gangwondo 26339, Korea.

\section{References}

Bae ES, Chang MH. Effect of natural surfactants addition on hair dyeing with safflower red colorants. Journal of the Korean Society of Design Culture, 24: 135-144, 2018.

Baek IY, Song YS, Lee KK. Natural dyeing characteristics and colorfastness on the hair of Monascus purpureus pigment. Journal of the Korean Society of Cosmetology, 23: 978-985, 2017.

Cha Wm, Kim HS. Natural dyeing of hair using Carthamus tinctorius. Journal of Investigative Cosmetology, 4: 177182, 2008.

Hong HS, Hong BS. Perceived risks and benefits to natural dyeing product: the role of product knowledge. Journal of the Korean Society of Clothing and Textiles, 32: 13431355, 2008.

Kang EJ, Ryu JW. Natural hair dyeing of Rubia tinctorum according to type of mordant, dyeing temperature. The Journal of the Korean Society of Make-up Design, 15: 37-48, 2019.

Kim CM, Lee YJ, Kim IR, Shin JH, Kim YL. Coloured illustrations for discrimination of herbal medicine. Academy, Seoul, pp396-398, 2014.

Kim JP, Lee JJ. Natural dyes in Korea: traditional dyes and natural dyeing technology. Seoul Natural University Press, Seoul, pp1-3, 2004.

Kim JS. Hair coloring. Kuhminsa, Seoul, p55, 2017.

Kim JS. Coloring power and changes in hair quality from natural pigment from red paprika. Asian Journal of Beauty and Cosmetology, 61: 369-379, 2018.

Kim JS, You SE. Natural dyeing materials from Opuntia humifusa for hair. Asian Journal of Beauty and Cosmetology, 63:129-138, 2019.

Kim JS. Effect of purple sweet potato on hair dyeing and hair texture improvement. Asian Journal of Beauty and Cosmetology, 65: 321-330, 2020.

Lee OK, Yoon YM, Lee HJ, An SK. The natural hair dyeing using extracts of the Pueraria thunbergiana root. Journal of the Society of Cosmetic Scientists of Korea, 36: 3339, 2010. 
Oh HJ, Jung YJ. Analysis of natural dye-based hair coloring. Oriental Art, 37: 165-184, 2017.

Seo BL, Roh SS. A philological study on poisoning of Arecae semen. The Journal of Jeahan Oriental Medical Academy,
10: 69-81, 2012.

Song HS, Kim BH. Beautiful our color, natural dyeing. Sookmyung Women's University Press, Seoul, p204. 2004. 


\section{국문초록}

\section{빈랑자 색소에 의한 모발 염색효과와 모질의 변화}

김주섭

상지대학교 뷰티디자인학과, 강원도 원주시, 한국

목적: 본 연구는 빈랑자 염료로 모발에 도포하여 염색효과와 모질 특성 변화를 알아보고자 하였다. 방법: 빈랑자 염료를 중탕하여 사용하였다. 염료를 건강모와 탈색한 시료 모발에 도포 후 열처리와 자연방치 시간을 다르게 한 후 시료별로 도포 전과 후를 측정 하여 비교 분석하였다. 염색효과를 알기 위해 색차계를 이용하여 $\mathrm{L}^{*}, \mathrm{a}^{*}, \mathrm{~b}^{*}$ 값과 물 빠짐을 측정하였다. 또한 모질 특성 변화를 알 기 위해 인장강도, 메틸렌블루를 이용한 흡광도, 광택을 측정하였다. 결과: 염색효과 측정 결과는 $\mathrm{L}^{*}$ 값은 건강모에서는 변화가 없고 $7 \mathrm{~L}(2)$ 과 $7 \mathrm{~L}(3), 9 \mathrm{~L}(3)$ 에서는 염색 효과가 있었다. $\mathrm{a}^{*}$ 값과 $\mathrm{b}^{*}$ 값은 도포 전과 후의 통계분석 결과 건강모는 변화가 없음을 알 수 있었 고, $7 \mathrm{~L}(1)$ 과 $7 \mathrm{~L}(2), 7 \mathrm{~L}(3), 9 \mathrm{~L}(3)$ 은 유의미한 결과로 염색 효과가 있었다. 물 빠짐 측정결과는 1일차에는 가장 많이 빠졌고, 3 일차부 터는 더 이상의 물 빠짐이 없었다. 인장강도 측정결과는 $7 \mathrm{~L}(1)$ 과 $7 \mathrm{~L}(2), 7 \mathrm{~L}(3), 9 \mathrm{~L}(3)$ 시료에서 통계분석 결과 모질의 특성 변화는 없 었다. 메틸렌블루를 이용한 흡광도 분석결과 건강모와 $7 \mathrm{~L}(1)$ 과 $7 \mathrm{~L}(2), 7 \mathrm{~L}(3), 9 \mathrm{~L}(3)$ 시료에서 통계분석 결과 모질의 특성 변화는 없 었다. 광택 측정결과는 통계분석 결과 광택에 변화를 주는 것을 알 수 있었다. 결론: 빈랑자 염료에 의한 모발 염색효과가 있었고, 모질의 특성 변화는 광택은 있고, 인장강도와 흡광도 변화는 없었다. 차후 다양한 염색 처리방법에 의한 염색효과 연구와 결과의 신 뢰성 확보를 위한 시료의 측정 회수를 늘릴 필요가 있다.

핵심어: 빈랑자, 염색효과, 모질, 모발, 염색

\section{참고문헌}

강은주, 류지원. 매염제의 종류-매염시간 및 염색온도에 따른 서양꼭두서니의 모발 천연염색. 한국메이크업디자인학회지, 15: 37-48, 2019.

김주섭. 헤어컬러링. 구민사, 서울, $\mathrm{p} 55,2017$.

김주섭. 적색파프리카 색소에 의한 모발 염색력과 모질의 변화. 아시안뷰티화장품학술지, 61: 369-379, 2018.

김주섭, 유세은. 백련초의 모발에 대한 천연염색 원료 연구. 아시안뷰티화장품학술지, 63:129-138, 2019.

김주섭. 자색고구마의 염색 효과와 모질 개선 효과 연구. 아시안뷰티화장품학술지, 65:321-330, 2020.

김재필, 이정진. 한국의 천연염료: 전통염료와 천연염색기술. 서울대학교풀판부, 서울, pp1-3, 2004.

김창민, 이영종, 김인락, 신전휘, 김양일. 한약재감별도감. 아카데미서적, 서울, pp396-398, 2014.

배은숙, 장미와. 홍화적색소에 의한 모발 염색의 천연 계면활성제 첨가에 따른 효과. 한국디자인문화학회지, $24: 135-$

$144,2018$.

백인영, 송연숙, 이근광. 홍국색소의 모발에 대한 천연 염색특성 및 견뢰도. 한국미용학회지, 23: 978-985, 2017.

서부일, 노성수. 종설: 빈랑의 독성에 곤한 문헌적 고찰. 제한동의학술원 논문집. 10: 69-81, 2012.

송화순, 김병희. 아름다운 우리의색, 천연염색. 숙명여자대학교 출판부, 서울, $\mathrm{p} 204,2004$.

이옥규, 윤영민, 이현진, 안성관. 칡뿌리 추출물을 이용한 천연 모발염색. 대한화장품학회지, $36: 33-39,2010$.

오현주, 정연자. 천연 염료를 이용한 모발 염색 연구. 동양예술, 37: 165-184, 2017.

차원미, 김한식. 홍화를 이용한 모발의 천연 염색. 대한미용학회지, 4: 177-182, 2008.

홍희숙, 홍병숙. 천연염색 의류제품에 대한 지각된 위험과 혜택: 천연염색 제품 지식에 따른 차이. 한국의류학회지, 32 :

1343-1355, 2008. 


\section{中文摘要}

\section{槟榔子色素的染发效果和头发质地的变化}

金周燮

尚志大学美容学科, 江原道原州市, 韩国

目的：本研究通过将槟榔子颜料涂在头发上来检验染发效果和头发质地特征的变化。方法: 将槟榔子颜料双煮 沸, 然后涂到健康和漂白头发两个样品上。样品经过热处理, 并在自然条件下放置不同小时。在施加之前和 之后测量样品并进行比较分析。为了量化染发效果, 使用色差仪测量 $\mathrm{L}^{*}$, $\mathrm{a}$ “和 $\mathrm{b}^{*}$ 值以及裉色。另外, 测量抗张 强度, 使用亚甲蓝的吸光度和光泽度以检查头发质地的变化。结果: 结果表明, 健康头发的 $L^{*}$ 值没有变化, 而 $7 \mathrm{~L}(2), 7 \mathrm{~L}(3)$ 和 $9 \mathrm{~L}(3)$ 的染发效果得到了观察。对 $\mathrm{a}^{*}$ 和 $\mathrm{b}^{*}$ 值的分析显示, 健康的头发保持不变, 而 $7 \mathrm{~L}(1), 7 \mathrm{~L}(2)$, $7 \mathrm{~L}(3)$ 和 $9 \mathrm{~L}(3)$ 的染发效果显着。在褪色方面, 最显着的褪色发生在第1天, 而第3天则没有注意到。使用样品 $7 \mathrm{~L}(1), 7 \mathrm{~L}(2), 7 \mathrm{~L}(3)$ 和 $9 \mathrm{~L}(3)$ 测试拉伸强度。，未观察到头发质地的变化。此外，在使用亚甲基蓝测量吸光度之 后, 对健康的头发和样品 $7 \mathrm{~L}(1), 7 \mathrm{~L}(2), 7 \mathrm{~L}(3)$ 和 $9 \mathrm{~L}(3)$ 进行了分析。没有发现头发质地的变化。最后, 毛发样品 在测量光泽度后没有表现出变化。结论: 该研究证实了槟榔子色素的染发作用。根据头发的质地, 观察到光泽的 变化, 而拉伸强度和吸光度保持不变。将来, 为了确保结果的可靠性和各种染发方法的研究, 有必要对较大的 样品进行研究。

关键词: 槟榔子, 染色效果, 头发纹理, 头发, 染料 